\title{
WISATA TEH: SEBUAH STUDI KASUS DI PANTJORAN TEA HOUSE
}

\author{
Giyatmi Giyatmi', Levyda Levyda ${ }^{2}$, Intan Nurul Azni ${ }^{3}$ \\ ${ }^{13}$ Fakultas Teknologi Pangan dan Kesehatan, Universitas Sahid \\ ${ }^{2}$ Fakultas Ekonomi dan Bisnis, Universitas Sahid \\ Jl. Soepomo No 84, Jakarta Selatan \\ Email Korespondensi: giyatmi@hotmail.com
}

\begin{abstract}
ABSTRAK
Dewasa ini Indonesia sedang menggalakkan sektor pariwisata melalui berbagai pendekatan, salah satunya adalah Pariwisata Gastronomi (Kuliner). Di berbagai negara, khususnya China, tradisi minum teh memiliki sejarah panjang, tidak terkecuali Indonesia yang menempati 10 negara terbesar produsen teh di dunia. Untuk mengetahui daya tarik meracik dan minum teh yang diharapkan memperkuat daya tarik wisata gastronomi, penelitian ini melakukan studi kasus di Pantjoran Tea House, yang berlokasi di wilayah Petak Sembilan, Jakarta.Hasil studi menunjukkan bahwa masyarakat yang gemar minum teh berusia muda dan berpendidikan tinggi. Jenis teh yang digemari adalah jenis teh bunga dengan frekuensi dua kali sehari. Umumnya, kebiasaan minum teh ditularkan melalui anggota keluarga lainnya. Wisatawan Pantjoran Tea House umumnya merupakan pengunjung baru dengan alasan tertarik dengan atraksi meracik teh. Wisatawan menyatakan bahwa mereka mendapat pengetahuan baru tentang teh; manfaat bagi kesehatan; cara meracik, menyajikan, dan menikmati teh dengan benar. Wisatawan menyebutkan tidak berkeberatan dengan harga yang dibayar dengan mendapat pengetahuan dan pengalaman baru. Wisatawan juga ingin datang lagi dan merekomendasikan pengalamannya kepada pihak lain.
\end{abstract}

Kata kunci: tea-tourism, tea-blending, gastronomy-tourism, pantjoran-tea-house

\begin{abstract}
Currently Indonesia is promoting the tourism sector through various approaches, one of which is Gastronomy Tourism. In many countries, especially China, the tradition of drinking tea has a long history including Indonesia which occupies the top 10 countries of tea producers in the world. To find out the attractiveness of mixing and drinking of tea expected to strengthen the gastronomic attraction, a case study was conducted at Pantjoran Tea House, located in Petak Sembilan area, Jakarta.The results showed that mostly people visiting PTH are young generation and highly educated who come not only from Jabodetabek area. Visitors do not have a special preference for the type of tea with the frequency of drinking tea once a day. Generally, tea drinking habits were transmitted through other family members. Tourists visiting PTH were generally new visitors with a reason meet with friends/relation. Tourists claim that they got new knowledge about tea and health benefits; as well as how to blend, serve, and enjoy tea properly. Tourists mentioned do not to object to the price paid by gaining new knowledge and experience. Tourists also get satisfaction so want to come again and recommend their experience to others. Based on the case in PTH can be concluded that the restaurant with unique packed in gastronomic be able to attract tourists.
\end{abstract}

Keywords: tea-tourism, tea-blending, gastronomy-tourism, pantjoran-tea-house 


\section{PENDAHULUAN}

Teh, kopi, dan kola merupakan tiga besar minuman yang banyak dikonsumsi di dunia (Yang, 2007). Teh merupakan bagian yang tidak dapat dipisahkan dari pelayanan makanan (Jolliffe, 2007). Teh merupakan minuman penyegar paling populer setelah kopi. Minuman ini sudah dikenal sejak berabad-abad lampau. Negara penghasil teh utama ada di Asia seperti Cina, Sri Lanka, Turki, India, Jepang, Vietnam, dan Indonesia, sisanya di Afrika dan Amerika Selatan.Direktur Jenderal Perdagangan Luar Negeri Kementerian Perdagangan Dody Edward menyebut, pada 2015, Indonesia merupakan menempati peringkat ke-7 produsen teh terbesar di dunia.

Kebiasaan minum teh sudah berlangsung sejak ratusan tahun yang lalu. Bahkan para tuan tanah dan pejabat di jaman kolonial Belanda di Indonesia memiliki perkebunan teh tersendiri. Bagi mereka itu menjadi simbol kekayaan yang dimiliki.Di Indonesia teh dikenal sejak 1686 saat seorang Belanda bernama Dr. Andreas Cleyer membawanya ke Indonesia. Semula teh hanya dipakai sebagai tanaman hias. Lama sesudah itu, pada 1728, pemerintah kolonial Belanda mendatangkan teh secara besar-besaran dari Cina untuk dibudidayakan di Pulau Jawa. Namun baru seabad kemudian, dengan dipelopori oleh Jacobson, teh menjadi komoditas yang menguntungkan, sehingga pemerintahan Gubernur Jenderal Van den Bosch menjadikan teh sebagai salah satu tanaman yang harus dibudidayakan melalui politik tanam paksa(Yulianti, 2008).

Teh termasuk komoditas perkebunan strategis. Konsumsi teh dunia selalu mengalami peningkatan. Bahkan di beberapa negara, minum teh sudah menjadi kebudayaan penting.Dewasa ini Indonesia sedang menggalakkan sektor pariwisata dari berbagai pendekatan, salah satunya adalah Pariwisata Gastronomi (kuliner). Pada studi kasus ini, dilakukan penelitian di salah satu restoran yang menyediakan minuman teh di daerah Glodok, Jakarta Barat bernama Pantjoran Tea House.

Di era Batavia pada masa lalu sampai sekarang, kawasan Kota merupakan kawasan niaga. Banyak orang berlalu lalang dan pedagang keliling yang merasa kelelahan dan kepanasan. Seorang Kapiten yang merupakan warga Tionghoa bernama Kapiten Gan Djie dan isterinya meletakkan delapan teko berisi air teh yang ditujukan bagi mereka yang menumpang beristirahat di depan kantornya. Delapan, atau pat dalam bahasa Tionghoa, menjadi asal muasal jalan tersebut yang kemudian dinamakan jalan Patekoan. Kantor/Gedung tersebut merupakan saksi sejarah kawasan Glodok, yang saat ini sedang dinominasikan kepada UNESCO sebagai World Heritage Site.Menurut sejarah, nama Glodok dan Pancoran merupakan plesetan dari pancuran yang diartikan sebagai sumber air bagi warga kota Batavia, maka daerah itu dikenal sebagai "Pancoran". Air dari pancuran yang menggerojok menimbulkan bunyi. "Grojok" dalam pelafalan orang Tionghoa atau Betawi didengar sebagai "Glodok". Gedung cagar budaya milik perseorangan ini direvatilisasi oleh arsitek konservasi selama 16 bulan sejak September 2014 dan diresmikan pada tanggal 15 Desember 2015 oleh CEO Jakarta Old Town Revitalization Corp (JOTRC). Gedung tersebut hingga saat ini dijadikan restoran dengan Pantjoran Tea House (Gambar 1). 


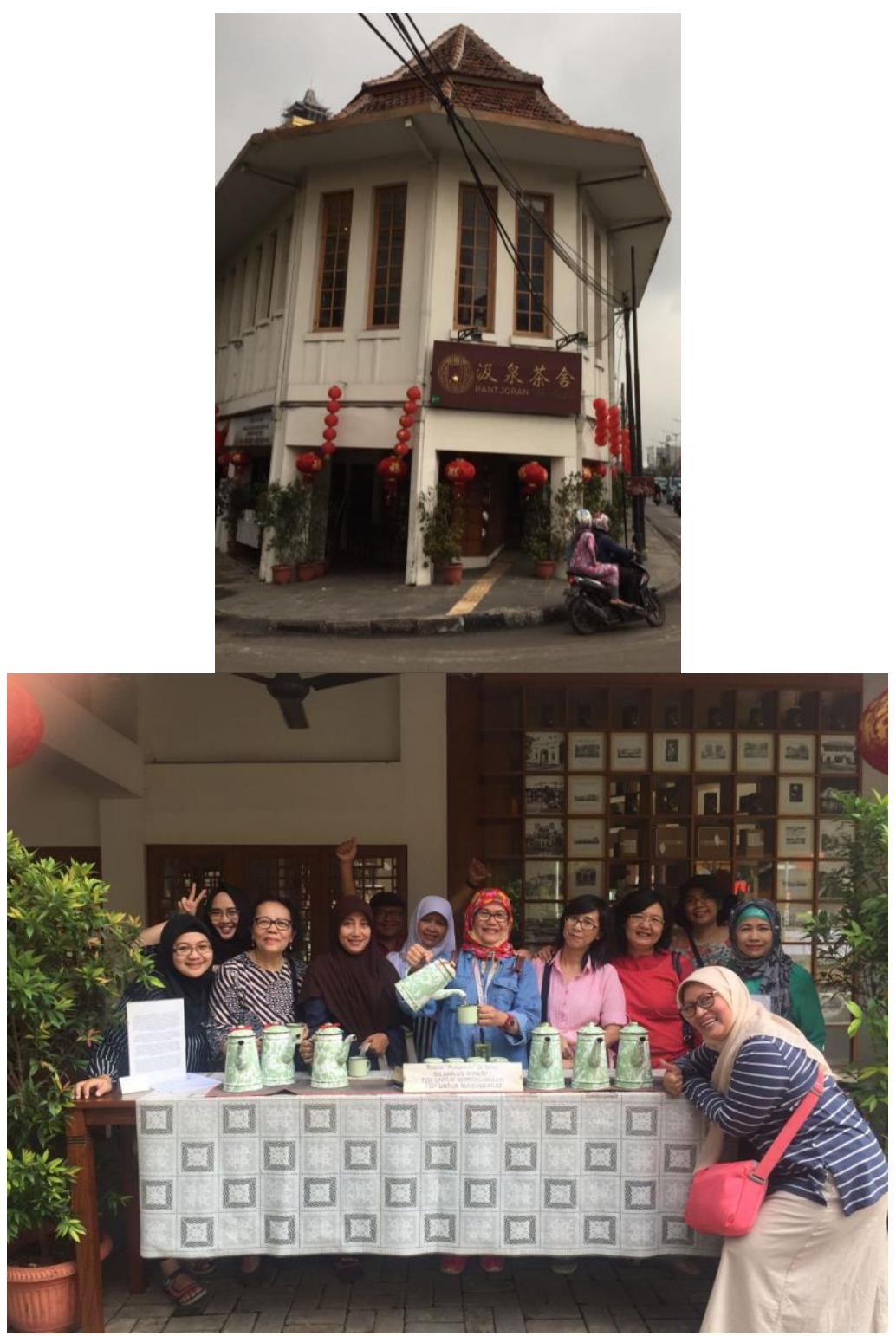

Gambar 1. Gedung Pantjoran Tea House saat ini yang menyediakan delapan teko minuman teh

Sumber: Dokumen Pribadi

Pantjoran Tea House merupakan restoran kekinian dengan spesialisasi teh. Teh yang disediakan berupa teh lokal dan ada juga yang impor (Jepang, China). Hal yang menarik dari Panjoran Tea House adalah tidak saja menyajikan teh yang enak, tetapi juga adanya atraksi meracik teh (Gambar 2). Atraksi ini memberikan pengetahuan tersendiri bagi para pengunjung, baik dalam mengenal bermacam macam teh, maupun cara meracik teh yang benar dan menyehatkan. Selain teh, di restoran tersebut juga menyediakan makanan yang berupa kudapan dan makanan berat dengan beragam pilihan, seperti nasi goreng, kweetiauw, dan lain-lain. 
Mengikuti definisi budaya, budaya teh juga dapat didefinisikan dalam arti luas dan sempit (Wu, 2006). Secara luas itu berarti total materi terkait teh dan kekayaan spiritual selama proses pengembangan teh, yang menggabungkan produk yang berwujud dan tidak berwujud termasuk demonstrasi etika, norma etiket, estetika, agama,seni dan teh, teknik dan bahan pengolahan teh (Song, 2004; Li, 2007); dan secara sempit itu hanya berarti kekayaan spiritual (Wang, 1992; Ning dan Liu, 2005). Studi tentang budaya teh tidak hanya populer di Cina, tetapi juga di Jepang, Inggris, Amerika Serikat, India, dan lain lain.

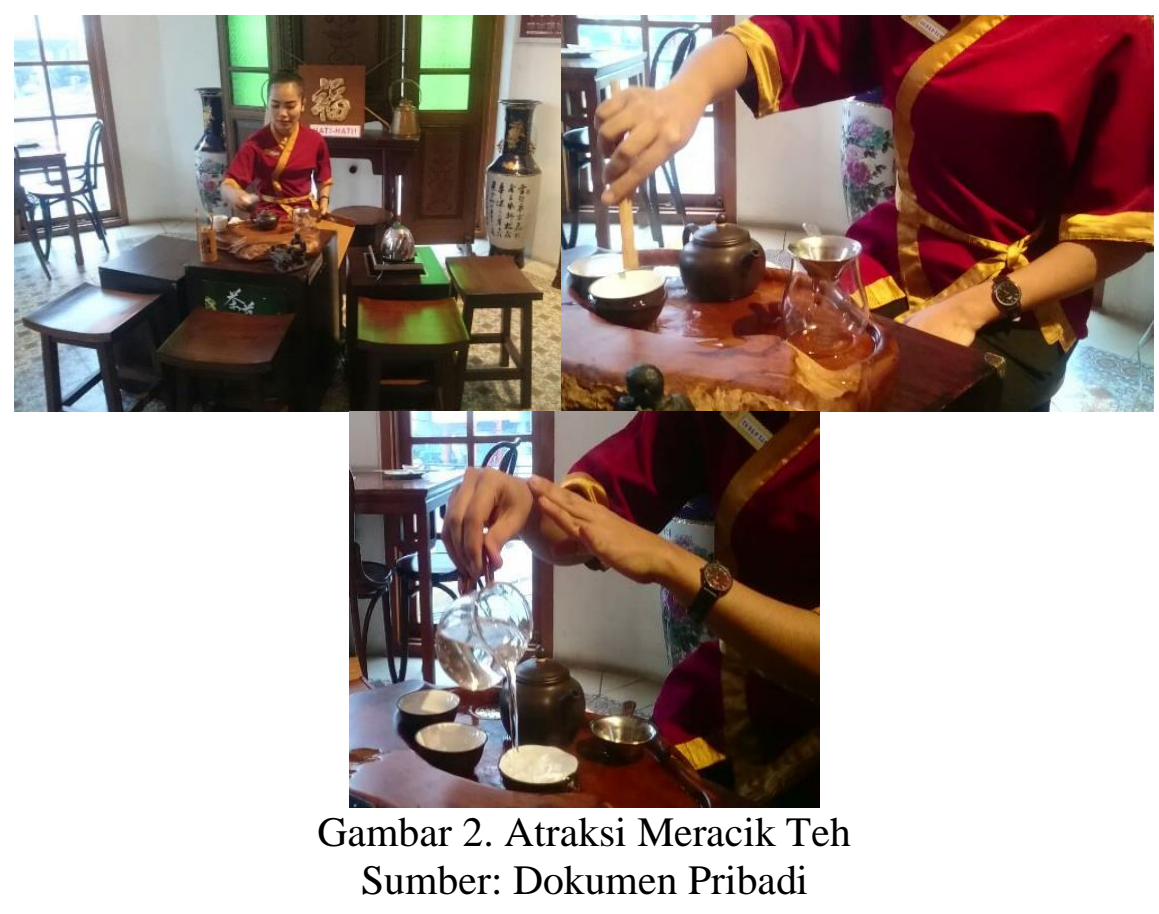

Dalam budaya Indonesia, minum teh adalah minum air yang mengandung seduhan daun teh. Untuk menambah nikmat, biasanya ditambahkan gula. Teh dapat disajikan pada pagi hari sambil menemani sarapan, maupun saat santai disore hari sambil ditemani pisang goreng hangat. Teh juga biasa disuguhkan jika ada tamu yang datang. Tidak ada aturan yang terdapat dalam minum teh ala Indonesia. Jika ingin minum teh, tinggal buat sendiri. Wadahnya pun sesuka hati, bisa menggunakan gelas dan bisa juga menggunakan cangkir (Yulianti, 2008).

Menurut Maryani dan Rejamardika (2013), ditemukan perbedaan yang cukup jauh mengenai gaya hidup minum teh di era 80 hingga 90 - an dengan masa kini. Konsumen teh masa kini justru menginginkan "lebih dari sekedar dari minum teh". Oleh sebab itu tradisi minum teh tidak lagi dilakukan di dalam rumah, melainkan di tempat ramai seperti di dalam mall, atau café, atau tea house. Konsumen teh ini mengharapkan suasana yang lebih nyaman dibandingkan di rumah. Acara minum teh ini tidak hanya dilakukan bersama keluarga saja, melainkan bersama teman-teman sebaya, atau bersama rekan bisnis. Acara minum teh yang dulunya hanya dilakukan pada pagi atau sore hari, kini dapat dilakukan setiap saat. Bahkan acara minum teh ini dapat dilakukan saat melakukan hubungan bisnis. Konsumen teh masa kini juga mengharapkan sensasi yang berbeda saat minum teh, oleh sebab itu konsumen ini mengharapkan rasa teh atau penyajian teh yang lebih bervariasi. Melihat adanya perubahan dalam gaya hidup minum teh di masyarakat, maka para pengusaha melihat hal ini sebagai sebuah peluang. Peluang ini dimanfaatkan 
oleh para enterpreneur dengan memunculkan tea house. Salah satu tea house yang cukup berkembang di Jakartayaitu Pantjoran Tea House. Maka dari itu, dilakukan studi kasus berupa analisa deskriptif terhadap pengunjung Pantjoran tea House yang bertujuan untuk mengetahui daya tarik minum teh yang diharapkan memperkuat daya tarik wisata gastronomi.

\section{METODE PENELITIAN}

Survei kuantitatif digunakan dalam studi kasus ini dengan menggunakan kuesioner yang sesuai untuk penelitian tentang keyakinan atau perilaku responden (Neuman, 2003). Kuesioner dibagi menjadi dua bagian, Kuesioner Bagian I berfokus pada informasi demografi sosial pengunjung, yaitupertanyaan tentang jenis kelamin, usia,asal daerah, pengetahuan umum mereka tentang teh, kebiasaan minum the mereka, dan tentang kunjungan mereka ke Panjtoran Tea House. Kuesioner Bagian IIberisi pernyataan tingkat kepuasan setelah mengunjungi Pantjoran Tea House seperti pengetahuan mengenai teh, cara meracik dan menikmati teh yang benar, pengalaman yang didapat, rekomendasi, serta mengenai fasilitas Pantjoran Tea House lainnya. Pertanyaan-pertanyaan ini untuk mengetahui tingkat kepuasan pengunjung setelah mengunjungi Pantjoran Tea House.Sebagian besar pertanyaan tertutup, namun ada juga beberapa pertanyaan terbuka yang meminta komentar tambahan. Pada kuesioner Bagian II, pengunjung sebagai responden menjawab pertanyaan dengan memilih pernyataansangat setuju, setuju, ragu ragu, kurang setuju, dan tidak setuju untuk mengukur sikap pengunjung. Kuesioner disajikan dalam Bahasa Indonesia karena ditujukan untuk wisatawandomestik dan lokasi survei tersebut merupakan tempat wisata domestik. Apabila bertemu dengan pengunjung dari manca negara, pengisian kuesioner dibantu dengan penterjemaan pertanyaanpertanyaan dalam kuesioner. Kuesioner kemudianditabulasi dan diolah menggunakansoftwareMicrosoft Excel. Data yang dihasilkan berupa grafik frekuensi.

\section{HASIL DAN PEMBAHASAN}

\section{A. Profil Pengunjung}

\section{Demografi Pengunjung}

Dari 66 pengunjung, $48 \%$ adalah pria dan 52\% adalah wanita, sehingga hal ini menunjukkan distribusi gender yang baik. Dari segi usia, pengunjungt dicakup oleh semua kelompok umur, dimana pengunjung usia <20 tahun paling banyak dengan $38 \%$. Latar belakang pendidikan pengunjung paling banyak merupakan Sarjana dengan persentase sebesar 55\%. Berdasarkan asal wilayah, pengunjung paling banyak berasal dari Daerah Khusus Ibukota Jakarta sebanyak 55\%. Detail masing - masing grafik tersebut dapat dilihat pada Gambar 3. 

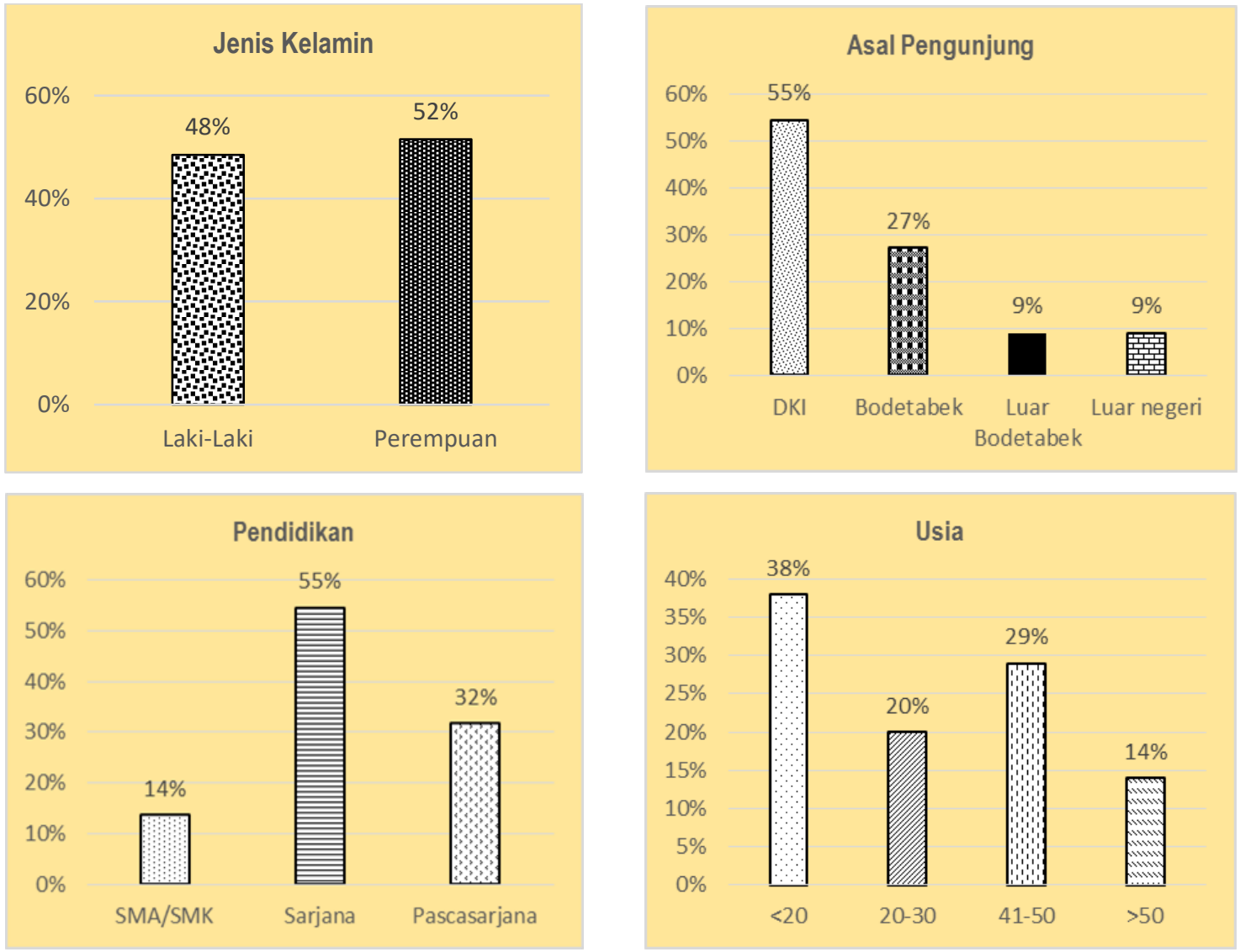

Gambar 3. Grafik Profil Pengunjung

Sumber: Data diolah oleh peneliti

\section{Kebiasaan Minum Teh Pengunjung}

Dari 66 pengunjung, $86 \%$ pengunjung biasa minum teh dan $14 \%$ pengunjung tidak biasa minum teh. Dari kuesioner yang ditanyakan, terdapat beberapa jenis teh yang biasa diminum, diantaranya jenis teh hitam, teh hijau, teh bunga. Dari grafik pada Gambar 4, dapat dilihat bahwa jenis teh yang biasa diminum paling banyak oleh pengunjung yaitu jenis teh hijau. Frekuensi minum teh para pengunjung setiap harinya rata - rata $1-2$ kali. Di lingkungan keluarga, terdapat anggota keluarga pengunjung yang minum teh sebanyak $68 \%$. Rata - rata pengunjung yang datang telah terbiasa meminum teh selama lebih dari 10 tahun dengan persentase pengunjung $64 \%$. 

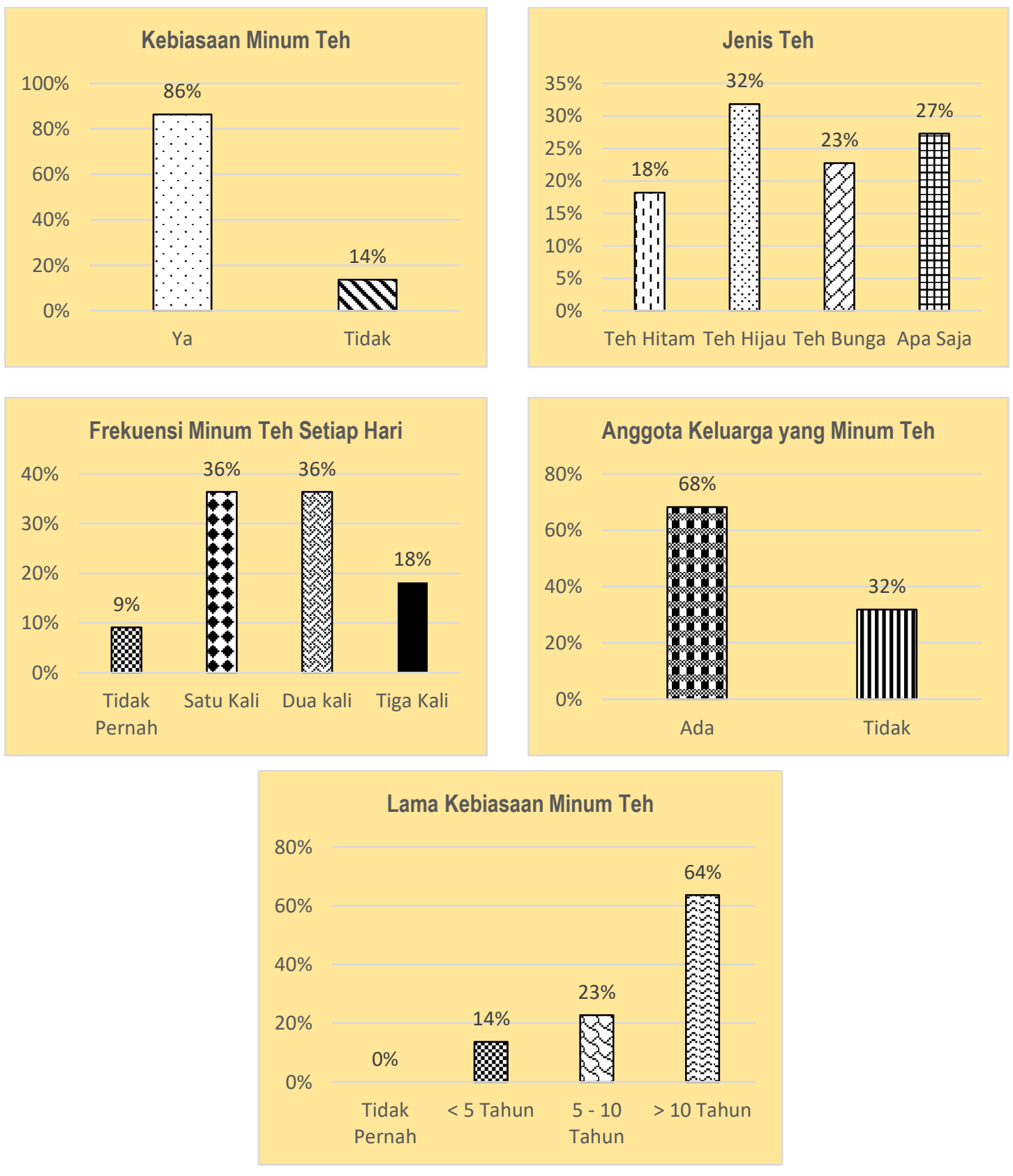

Gambar 4. Grafik Kebiasaan Minum Teh Pengunjung

Sumber: Data diolah oleh peneliti

\section{Kunjungan ke Pantjoran Tea House (PTH)}

Dari hasil kuesioner, pengunjung yang datang berkunjung untuk kedua kalinya sebanyak 55\%, sedangkan yang baru pertama kali berkunjung sebanyak 45\%.Dari 66 pengunjung, sebanyak 36\% mengenal Pantjoran tea House dari teman dan lainnya, sedangkan sisanya $27 \%$ mengenal dari media sosial. 
Alasan pengunjung memilih lainnya antara lainkarena ingin minum teh, kebetulan lewat sehingga tertarik mencoba, melihat Patekoan didepan restoran,tertarik dengan dekorasi restoran yang unik, dan terkesan dengan bangunannya yang cukup bersejarah.
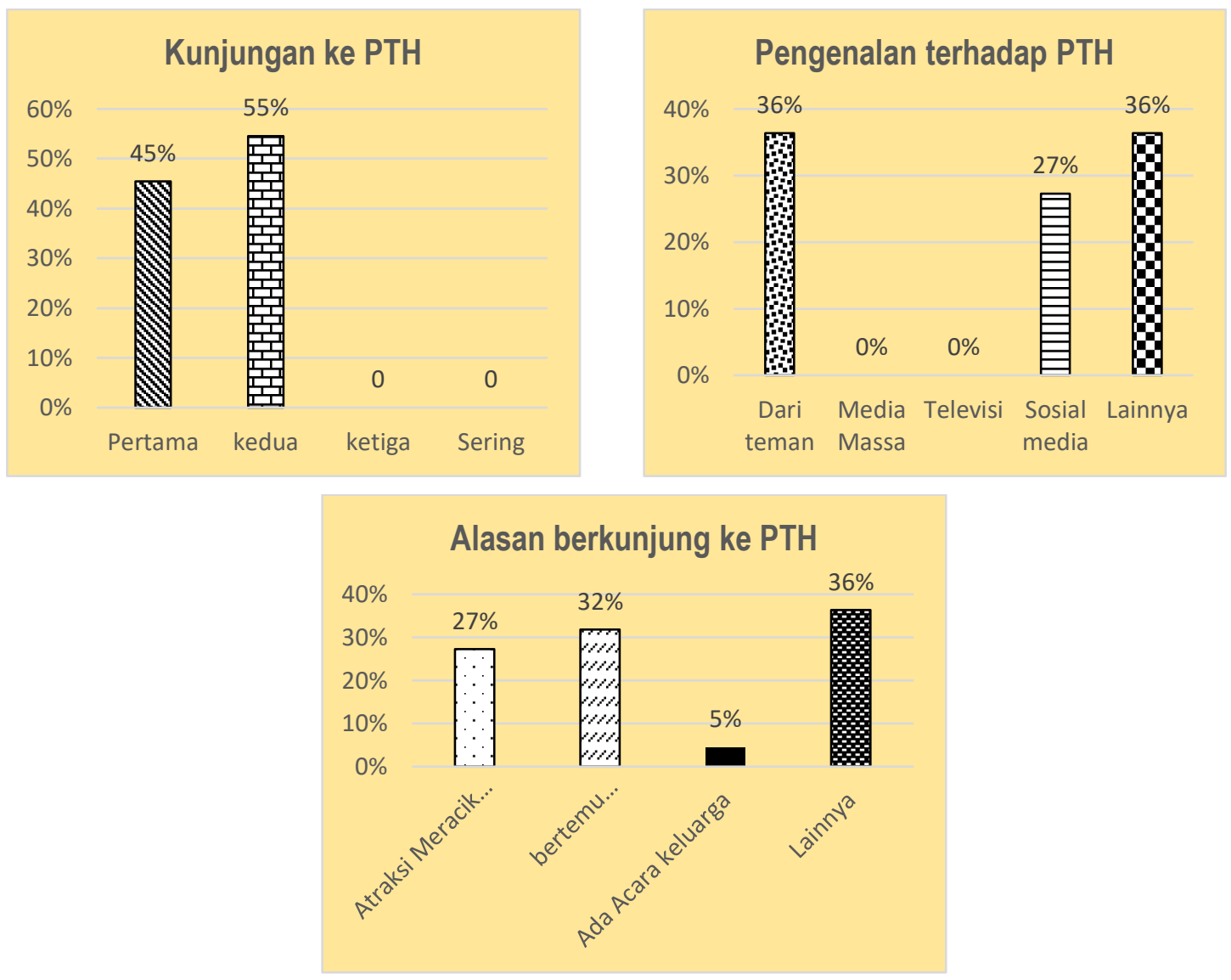

Gambar 5. Grafik Kunjungan ke Pantjoran Tea House

Sumber: Data diolah oleh peneliti

\section{B. Tingkat Kepuasan Pengunjung}

\section{Tingkat Kepuasan terhadapPengetahuan yang Diperoleh dari Pantjoran Tea House}

Tingkat kepuasan pengunjung terhadap pengetahuan yang diperoleh dari Pantjoran Tea House dapat dilihat pada Gambar 6. Setelah mengunjungi Pantjoran Tea House, untuk pernyataan pertama mengenai pengunjung mendapat pengetahuan baru tentang jenis teh dan manfaatnya, sebanyak $50 \%$ pengunjung menyatakan setuju, $36 \%$ pengunjung menyatakan sangat setuju, dan $14 \%$ pengunjung menyatakan ragu - ragu. Untuk pernyataan kedua mengenai pengunjung mendapat pengetahuan baru tentang cara mengolah/membuat teh yang benar, sebanyak $36 \%$ pengunjung meyatakan setuju, $27 \%$ pengunjung menyatakan sangat setuju, $23 \%$ pengunjung menyatakan ragu - ragu, dan $14 \%$ pengunjung menyatakan kurang setuju. 
Untuk pernyataan ketiga mengenai pengunjung mendapat pengetahuan baru tentang cara penyajian teh yang benar, sebanyak $50 \%$ pengunjung meyatakan setuju, $27 \%$ pengunjung menyatakan sangat setuju, $14 \%$ pengunjung menyatakan kurang setuju, dan 9\% pengunjung menyatakan ragu - ragu. Untuk pernyataan keempat mengenai pengunjung mendapat pengetahuan baru tentang cara menikmati teh yang benar, sebanyak $36 \%$ pengunjung meyatakan setuju, $27 \%$ pengunjung menyatakan sangat setuju, 18\% pengunjung menyatakan kurang setuju, dan $18 \%$ pengunjung menyatakan ragu - ragu. Untuk pernyataan kelima terkait pengunjung mendapat pengetahuan budaya Tiongkok, sebanyak 32\% pengunjung meyatakan ragu - ragu, 27\% pengunjung menyatakan setuju, $23 \%$ pengunjung menyatakan sangat setuju, dan $18 \%$ pengunjung menyatakan kurang setuju.
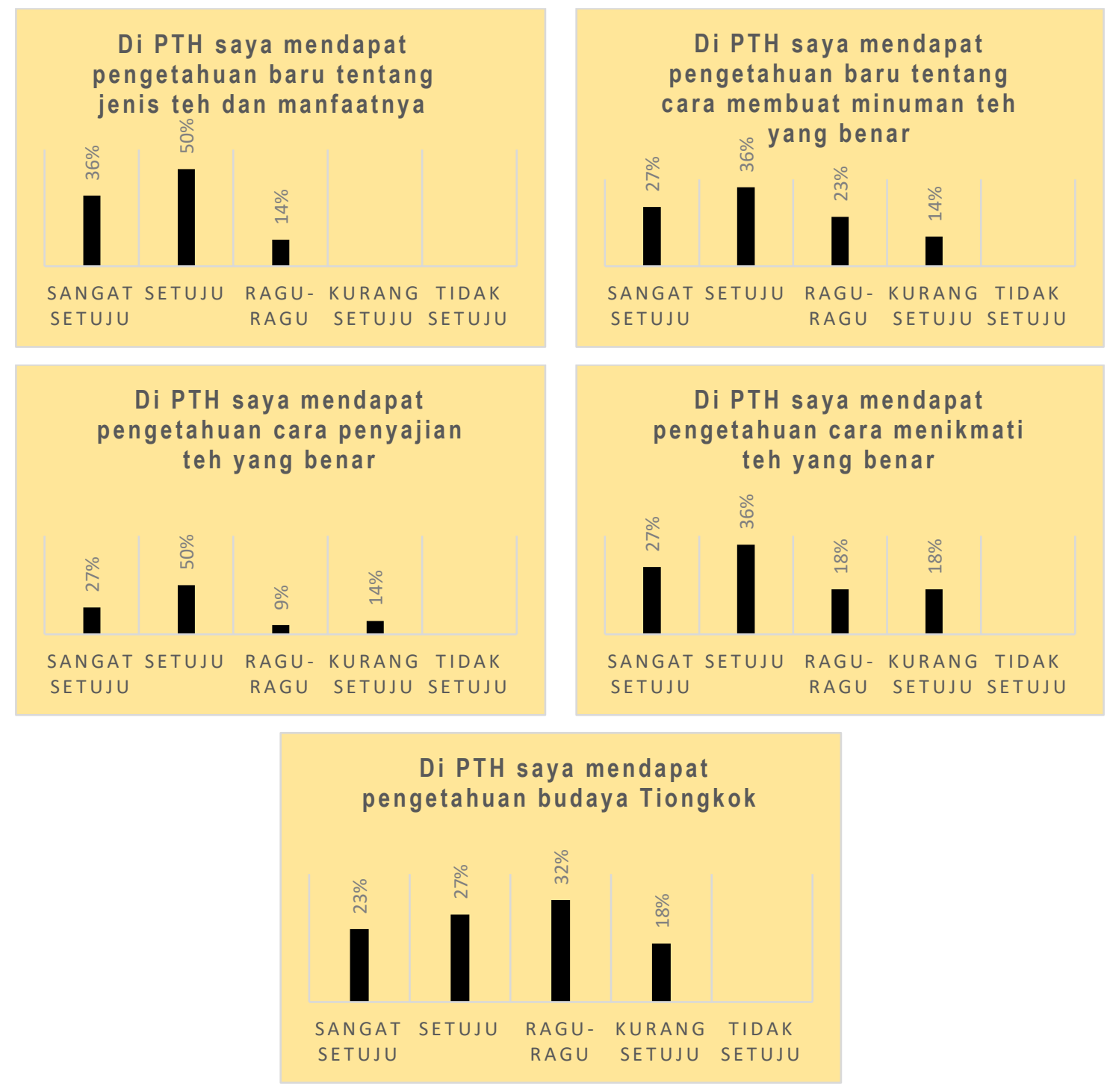

Gambar 6. GrafikTingkat Kepuasan terhadap Pengetahuan yang Diperoleh dari Pantjoran Tea House

Sumber: Data diolah oleh peneliti 


\section{Tingkat Kepuasan terhadap Pengalaman yang didapatkan dari Pantjoran Tea House}

Tingkat kepuasan pengunjung terhadap pengalaman yang didapatkan dari Pantjoran Tea House dapat dilihat pada Gambar 7. Setelah mengunjungi Pantjoran Tea House, untuk pernyataan pertama mengenai tingkat kesukaan pengunjung belajar jenis teh dan manfaatnya, sebanyak $64 \%$ pengunjung menyatakan setuju, $23 \%$ pengunjung menyatakan sangat setuju, 9\% pengunjung menyatakan ragu - ragu, dan 5\% pengunjung menyatakan kurang setuju. Untuk pernyataan kedua mengenai tingkat kesukaan pengunjung belajar budaya tata cara minum teh, sebanyak $59 \%$ pengunjung meyatakan setuju, $23 \%$ pengunjung menyatakan sangat setuju, $14 \%$ pengunjung menyatakan ragu ragu, dan $5 \%$ pengunjung menyatakan kurang setuju. Untuk pernyataan ketiga mengenai kesenangan pengunjung mendapatkan pengalaman baru, sebanyak $64 \%$ pengunjung menyatakan setuju, $27 \%$ pengunjung menyatakan sangat setuju, dan $9 \%$ pengunjung menyatakan ragu - ragu.

Untuk pernyataan keempat mengenai pengunjung tidak keberatan membayar lebih mahal untuk pengalaman baru, sebanyak $68 \%$ pengunjung menyatakan setuju, $14 \%$ pengunjung menyatakan sangat setuju, 9\% pengunjung menyatakan kurang setuju, dan $9 \%$ pengunjung menyatakan ragu - ragu. Untuk pernyataan kelima mengenai pengalaman yang didapatkan sebanding dengan yang pengunjung bayar, sebanyak $55 \%$ pengunjung menyatakan setuju, 23\% pengunjung menyatakan ragu - ragu, $18 \%$ pengunjung menyatakan sangat setuju, dan $5 \%$ pengunjung menyatakan kurang setuju.Untuk pernyataan keenam mengenaitingkat kepuasan pengunjung mendapatkan pengalaman baru, sebanyak $55 \%$ pengunjung menyatakan setuju, 32\% pengunjung menyatakan sangat setuju, $9 \%$ pengunjung menyatakan ragu - ragu, dan $5 \%$ pengunjung menyatakan kurang setuju.Untuk pernyataan ketujuh mengenai keinginan pengunjung untuk datang lagi, sebanyak $86 \%$ pengunjung menyatakan setuju dan $14 \%$ pengunjung menyatakan sangat setuju. Untuk pernyataan kedelapan mengenai keinginan pengunjung untuk merekomendasikan Pantjoran Tea House ke keluarga atau teman, sebanyak 77\% pengunjung menyatakan setuju, $18 \%$ pengunjung menyatakan sangat setuju, dan 5\% pengunjung menyatakan ragu - ragu.
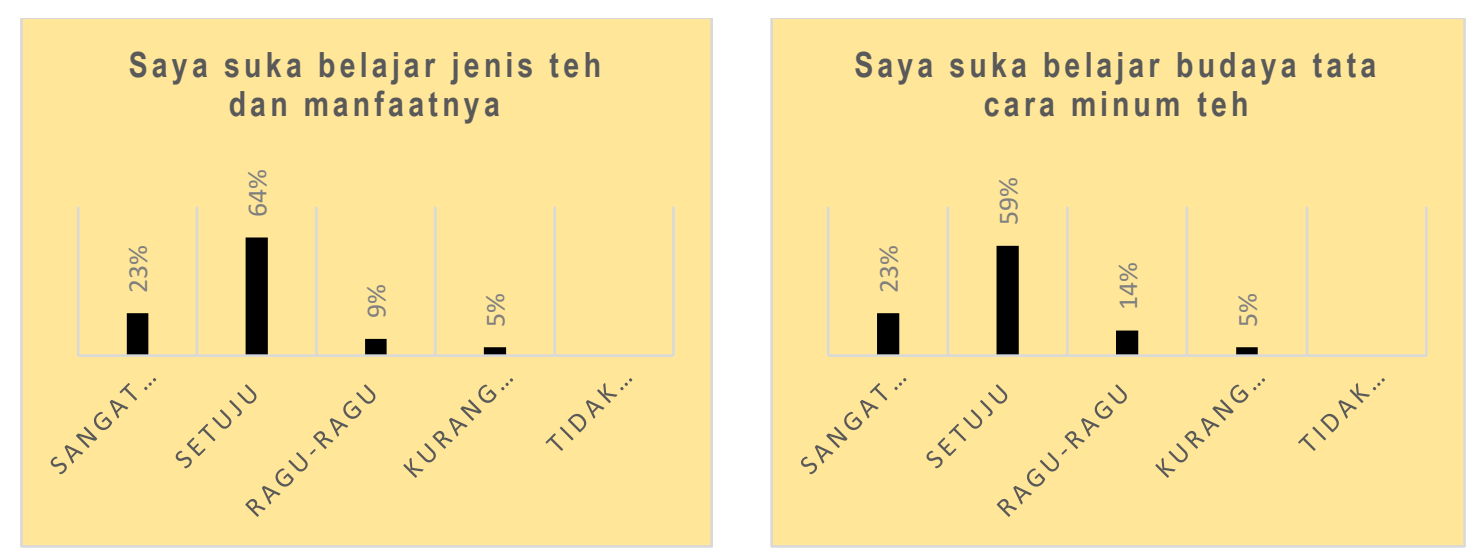

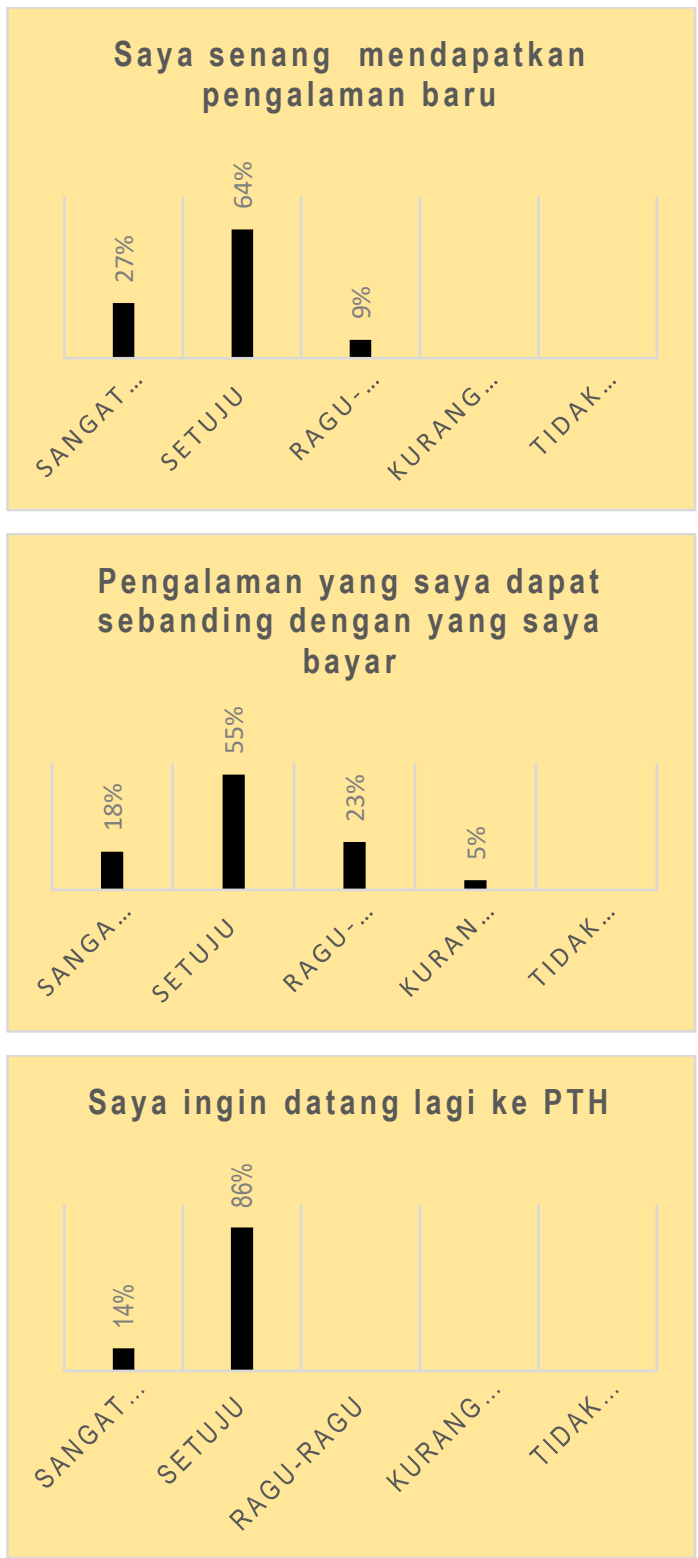
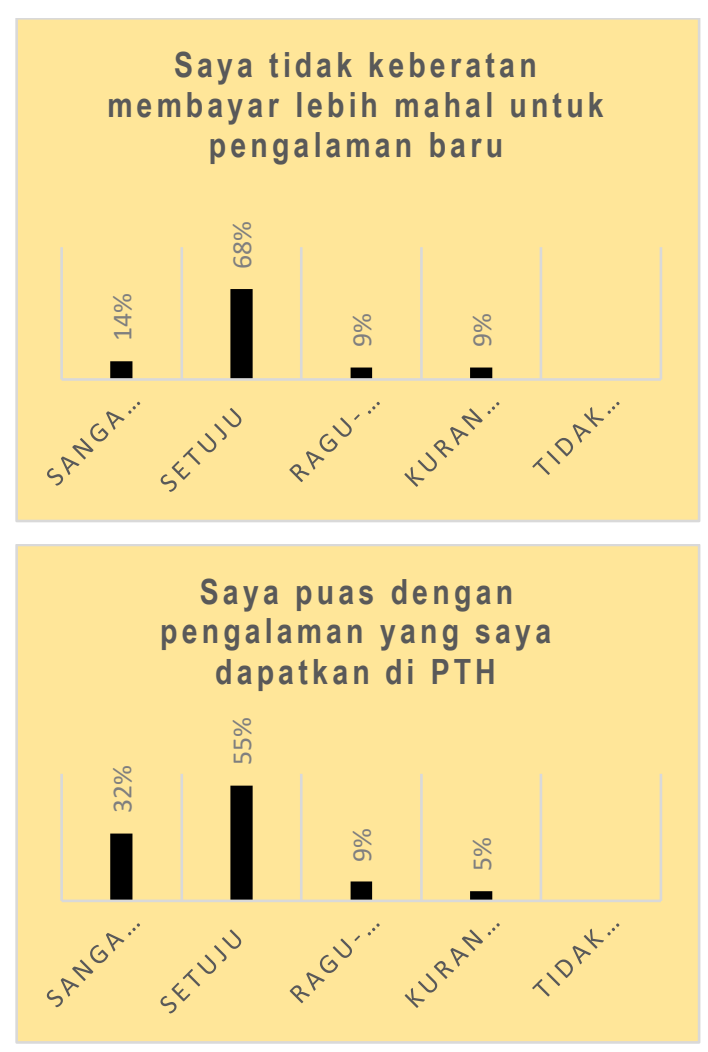

\section{Saya akan merekomendasikan} PTH kepada keluarga/teman

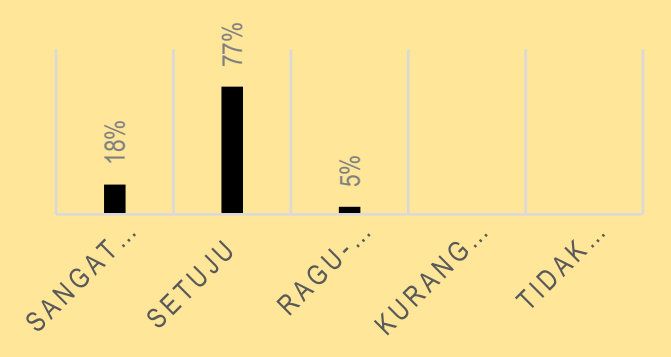

Gambar 7. Grafik Tingkat Kepuasan terhadap Pengalaman yang didapatkan dari Pantjoran Tea House

Sumber: Data diolah oleh peneliti

\section{Tingkat Kepuasan terhadap Menu, Desain, dan Pelayanan Pantjoran Tea House}

Tingkat kepuasan pengunjung terhadap menu, desain, dan pelayanan Pantjoran Tea House dapat dilihat pada Gambar 8. Setelah mengunjungi Pantjoran Tea House, untuk pernyataan pertama mengenai makanan dan minuman yang disajikan sangat baik, sebanyak $73 \%$ pengunjung menyatakan setuju, $18 \%$ pengunjung menyatakan sangat setuju, $5 \%$ pengunjung menyatakan ragu - ragu, dan $5 \%$ pengunjung menyatakan kurang setuju. Untuk pernyataan kedua mengenai desain restoran yang sangat unik, sebanyak $45 \%$ pengunjung menyatakan sangat setuju, $41 \%$ pengunjung menyatakan setuju, dan $14 \%$ pengunjung menyatakan ragu - ragu. Untuk pernyataan ketiga mengenai pelayanan 
restoran yang sangat baik, sebanyak $64 \%$ pengunjung menyatakan setuju, $27 \%$ pengunjung menyatakan sangat setuju, dan $9 \%$ pengunjung menyatakan ragu - ragu.
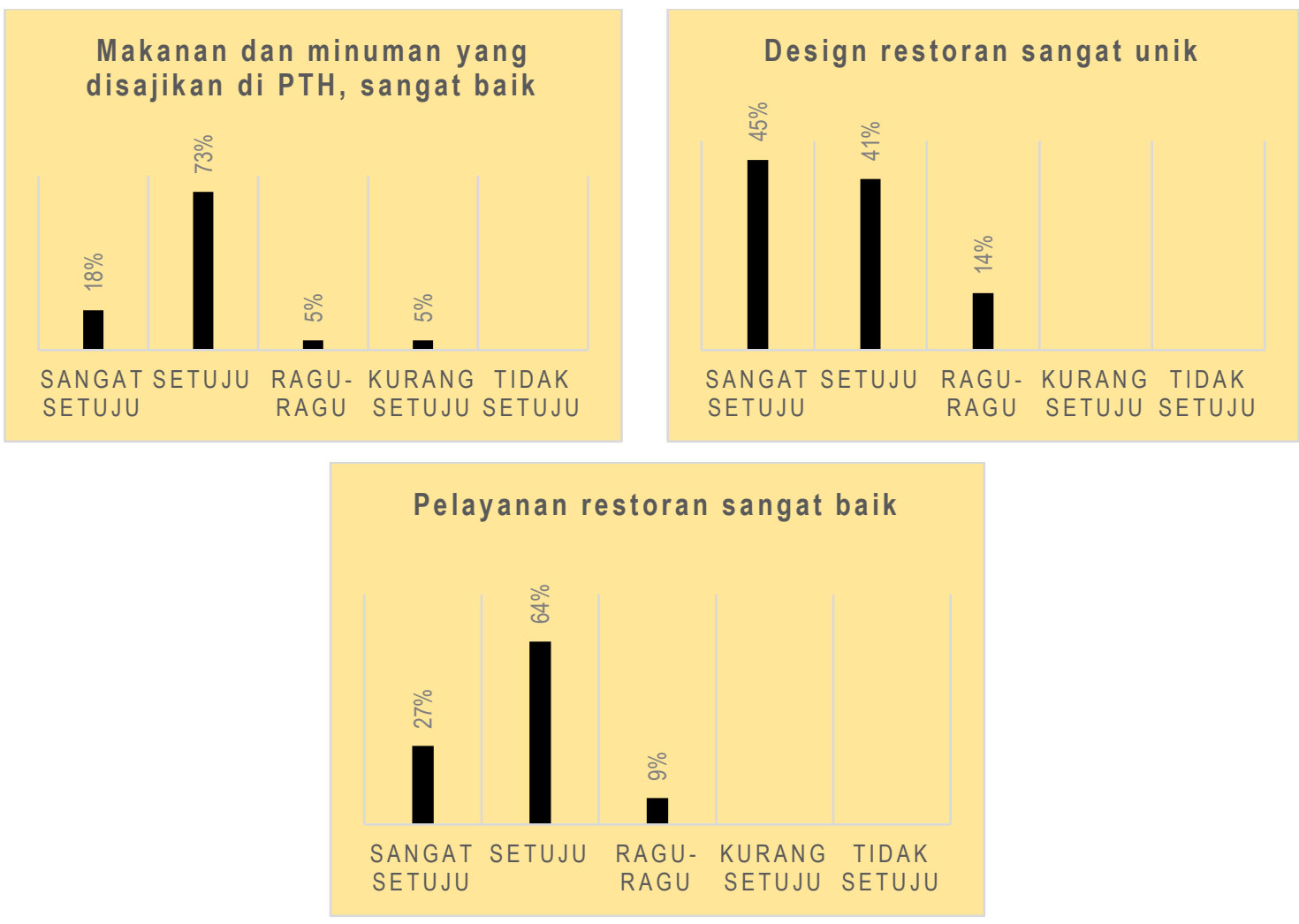

Gambar 8. Grafik Tingkat Kepuasan terhadap Menu, Design, dan Pelayanan Pantjoran Tea House

Sumber: Data diolah oleh peneliti

\section{KESIMPULAN}

Dari hasil studi kasus, dapat disimpulkan bahwa pengunjung Pantjoran Tea House berusia muda dan berpendidikan tinggi. Asal daerah pengunjung sebagian besar dari wilayah DKI Jakarta dan BOTABEK (Bogor, Tangerang, Bekasi). Pengunjung memiliki kebiasaan minum teh lebih dari 10 tahun dengan frekuensi $1-2$ kali sehari, tetapi tidak memiliki preferensi khusus terhadap jenis teh. Umumnya, kebiasaan minum teh ditularkan melalui anggota keluarga lainnya. Wisatawan Pantjoran Tea House umumnya merupakan pengunjung baru atau kunjungan kedua, dengan alasan bertemu dengan teman/relasi, dan mengetahui tempat tersebut dari teman atau media sosial. Mereka senang mendapat pengetahuan baru tentang jenis teh dan manfaat bagi kesehatan; cara meracik, menyajikan, dan menikmati teh dengan benar. Wisatawan juga menyebutkan tidak berkeberatan dengan harga yang dibayar dengan mendapat pengetahuan dan pengalaman baru. Pengunjung mendapatkan kepuasan tersendiri sehingga ingin datang lagi dan merekomendasikan pengalamannya kepada pihak lain. Selain menyajikan atraksi teh, pengunjung juga menyatakan bahwa makanan yang disajikan sangat baik, desain restoran unik, dengan pelayanan yang juga sangat baik. Berdasarkan kasus di Pantjoran 
Tea House dapat disimpulkan bahwa restoran dengan mengedepankaan branding satu jenis sajian namun dikemas dengan cara unik mampu menarik wisatawan.

\section{DAFTAR PUSTAKA}

Putra, D.A. (2016). Peringkat 7 Penghasil Teh Terbesar Dunia Tapi Produk RI Kalah Saing. https://www.merdeka.com/uang/peringkat-7-penghasil-teh-terbesar-duniatapi-produk-ri-kalah-saing.html. Di unduh tanggal 24 Maret 2018

Jolliffe, L. ed. (2007). Tea and tourism: Tourists, traditions and transformations (Vol. 11). Channel View Publications.

Li, W. (2007). Tea cultural tourism: a new model of cultural eco-tourism — case study on the tea cultural eco-tourism in Yunnan. Academic Exploration, 1, pp.137-140.

Yovita, D \& Rejamardika, Y.N. (2013). Analisis Deskriptif Tentang Gaya Hidup Minum Teh Masyarakat Surabaya di Hare and Hatter Cabang Surabaya Town Square. Jurnal Hospitality dan Manajemen Jasa, 1(2), pp.450-457.

Neuman, L. (2000). Social Research Methods: Qualitative and Quantitative Approaches (5th edn). Allyn and Bacon: Boston.

Ning, X \& Liu, Q. (2005). Study on the tea cultural tourism development in Jiangxi. Journal of Agriculture Archaeology, 4, pp.10-18.

Song, Y., Cui, S. \& An, Y. (2004). On the Chinese tea culture. Journal of Socialist College of Hebei, 1, pp.76-78.

Cheng, S.W., Xu, F.F., Zhang, J. \& Zhang, Y.T. (2010). Tourists' Attitudes Toward Tea Tourism: A Case Study in Xinyang, China. Journal of Travel \& Tourism Marketing, 27(2), pp.211-220.

Wang L. (1992). Chinese Tea Culture. China Bookstore: Beijing. (In Chinese)

$\mathrm{Wu}, \mathrm{T}$. (2006). Developing tea tourism in Meitan. Journal of Tea in Guizhou, 2, pp.2629.

Yang, Z. (2007). October. Tea culture and Sino-American tea connections. In Chinese American Forum (Vol. 23, No. 2, pp. 8-14).

Yulianti, A. D. (2008). Analisis Adaptasi Upacara Minum Teh (Chanoyu) di Indonesia.Universitas Sumatera Utara: Medan [Skripsi]

https://kabar10.com/negara-penghasil-teh/ [24 Maret 2018]

https://www.kompasiana.com/sutiono/pantjoran-tea-house-resto-kekinian-di-kawasanglodok_58e1a600bf22bdf1048b456a. [24 Maret 2018] 